\title{
Research on the cultivation of applied innovative talents in art design under the background of new liberal arts construction based on Cocos Digital Technology
}

\author{
Jianjie Gao ${ }^{1}$, Wenqing Lai $^{2}$, Xiurong Huang ${ }^{3}$ \\ ${ }^{1}$ Department of Humanities, Gannan University of Science and Technology, Ganzhou City, Jiangxi Province, China \\ 2 Department of Humanities, Gannan University of Science and Technology, Ganzhou City, Jiangxi Province, China \\ ${ }^{3}$ Department of Humanities, Gannan University of Science and Technology, Ganzhou City, Jiangxi Province, China
}

\begin{abstract}
In today's new era of digital technology-driven innovation, the continuous development of information technology has brought reforms and innovations to the education field, and has injected new vitality into the modernization of education in my country. The use of information technology to promote educational reforms is incorporated into education related policies. Innovation is the driving force of national development, and it is also the focus of international competition and talent training under the background of economic globalization. The construction of new liberal arts is an innovative development measure for China's higher liberal arts education in the new era. It is the emphasis and requirement of liberal arts in the development of science and technology today. In the context of the new liberal arts, the training of art design professionals should be cross-integrated with computer science, information technology and other disciplines, combined with the development and needs of regional digital industries, breaking professional boundaries, and mastering cutting-edge technology on the premise of adhering to the core values of art and design education. At the same time, reconstruct the talent training model. This article elaborated on the development trend of digital and informatization of art design education in the talent training and discipline construction of the art design major, and the official team of Cocos Engine-Yaji Software to build the Cocos Digital Technology Industry College to create a new mode of efficient integration of production and education., To build a unique digital art talent training system, to effectively connect the talent chain and the industrial chain, to promote the industrialization of academic achievements, to cultivate application-oriented talents that meet the needs of the digital industry, and to promote the construction of a new liberal arts major in art design.
\end{abstract}

\section{INTRODUCTION}

"New liberal arts" is a new concept put forward in recent years along with the development trend of my country's social sciences in the new era. In 2018, the Ministry of Education issued a guiding document and decided to implement the "Six Excellence and One Top" plan 2.0. In May 2019, the Ministry of Education, together with the Ministry of Science and Technology, the Ministry of Industry and Information Technology, and other 13 departments launched the plan "2.0" in Tianjin, and comprehensively promoted it. The construction of "new liberal arts, new engineering, new medical, and new agricultural sciences"[1].In November 2020, under the guidance of the Higher Education Department of the Ministry of Education, the New Liberal Arts Working Group of the Ministry of Education held a new liberal arts construction work conference at Shandong University[2].In 2021, the Higher Education Steering
Committee of the Ministry of Education and the China Association for Higher Education proposed to implement the requirements of the new liberal arts construction work conference, comprehensively promote the construction of the new liberal arts, and build a world-class, Chinese-characterized humanities talent training system [3], thus, China's new liberal arts construction has begun Ran slowly prelude.

Today, the rapid development of digital technology has brought tremendous changes to social lifestyles, industrial structure and economic development, and is also reshaping people's cognition and way of thinking to a large extent. At present, in order to improve the quality of human capital and use information technology supported by digital technology to deepen industrial development, various countries have issued relevant development plans to promote a new leap in their own economies. From Germany' s "Industry 4.0", the United States"

"National Strategic Plan for Advanced Manufacturing", the United Kingdom's “Industry 2050 Plan” and 
France's “Industrial New France", my country has clearly stated in the "14th Five-Year Plan" that digitalization must be accelerated. Development, the scale of the digital economy will exceed 60 trillion yuan by 2025. Digital technology has brought about disruptive and rich new formats, and it has also had a profound impact on education. New technological revolutions and industrial changes have increasingly demanded multidisciplinary, interdisciplinary, and innovative talents. Therefore, how to combine industrial development and social needs, combine art design with digital technology, cultivate new digital art design talents that adapt to the development trend of contemporary education, and promote new changes in art design education have become new thinking and new propositions in the art design field.

\section{Cocos DIGITAL TECHNOLOGY AND ITS INDUSTRIAL ECOSYSTEM}

The official team of Cocos Engine-Yaji Software, was registered and established in Xiamen, China on December 30, 2011. With deep technical background and years of experience in the game industry, it independently developed the "Cocos Engine" series of products, including the second generation of games Editors Cocos Creator, Cocos Creator 3D, the world's popular open source engine framework $\operatorname{Cocos} 2 \mathrm{~d}-\mathrm{x}$ and other products. It has been committed to providing advanced technology and services for the digital content industry, allowing developers to focus on digital content creation, and at the same time, working with industry partners to build an open and pragmatic mobile game ecosystem.

Cocos currently has 1.4 million registered developers worldwide, 300,000 monthly active developers, covering more than 203 countries and regions around the world, covering more than 1.5 billion player devices, games developed with Cocos engine cover all categories in the market, and in mobile games The Chinese market share accounts for $45 \%$, and the global market share accounts for $30 \%$. It is an excellent open source mobile game engine. In addition, the Cocos engine $R \& D$ and commercial teams are distributed in Beijing, Shenzhen, Shanghai, Xiamen, San Francisco, and New York. It is a domestically produced digital content development platform that operates globally. It has the world's leading user base and has occupied China's best-selling T20 in the mobile game market. $70 \%$ share. Service users cover: digital entertainment industry, online education industry, virtual reality, in-vehicle digital technology, online exhibition and other digital technology industries. Well-known industry users include: Huawei, ByteDance, Tencent, Facebook, Ubisoft, Disney, NetEase, New Oriental, Good Future, Xiaomi, Tesla, Mercedes-Benz, etc., during the 2020 epidemic, they will break technical barriers and become 2020 The technology provider of Shanghai Chinajoy Online Exhibition. In 2019, it became an in-depth partner of Huawei Cloud Game Management Platform to jointly build the Huawei ecosystem and promote the upgrade of the digital content industry.
While the Cocos engine plays the role of technical support in the industry, it has focused on building an educational ecosystem in the past ten years. It has opened cocos courses in first-class universities such as Peking University, Zhejiang University, Beijing Institute of Technology, Beijing Jiaotong University, University of Electronic Science and Technology, Xiamen University, etc. And with the parent company Beijing Touch Technology as the main body, it became the first batch of industry-academic cooperation and collaborative education support enterprises of the Ministry of Education

\section{SEVERAL PROBLEMS TO BE SOLVED URGENTLY IN THE CULTIVATION OF APPLIED INNOVATIVE TALENTS FOR ART DESIGN MAJORS}

- New industries, new formats, and new technologies continue to emerge, putting forward new requirements for the cultivation of art and design professionals. Focusing on the concept of cultivating applied innovative talents in art design, it is imperative to introduce enterprises and projects into schools. Especially as the country vigorously develops the digital economy, promotes digital industrialization and industrial digitization, and creates high-quality development of the digital economy, there is a shortage and imbalance in the supply and demand of talents in the digital technology industry;

- The original art design professional discipline construction process lacks industry guidance, professional training objectives, curriculum settings, practical teaching links, etc. are lagging behind the industry development speed, and the content of professional courses and internship training links need to be changed;

- The communication and cooperation between school teachers and industry teachers in the talent training work is broken, which makes the talent training process imperfect, and the theoretical and experimental teaching links and actual combat projects are out of touch;

- In the process of introducing industry experts and local industries, schools and enterprises need to achieve long-term win-win cooperation goals in talent selection, project docking, achievement realization, and scientific research support.

\section{THE REFORM AND INNOVATION OF ART DESIGN PROFESSIONAL TALENT TRAINING AND THE CONSTRUCTION PATH OF COCOS DIGITAL TECHNOLOGY INDUSTRY COLLEGE}

Notice of the "Guidelines for the Construction of Modern Industry College (Trial)" issued by the General Office of the Ministry of Education and the General Office of the Ministry of Industry and Information Technology on July 30, 2020. The guide points out: "Cultivating high-quality applied, compound, and innovative talents that adapt to 
and lead the development of modern industries is an inevitable requirement for higher education to support the high-quality development of the economy, and an important measure to promote the classified development and characteristic development of universities.[4]" In the context of the construction of new liberal arts, we need to re-understand the boundaries between disciplines and majors. Each major does not exist independently. It must have some internal connection or interdependence with other related majors, and the relevant knowledge of disciplines The overlapping and blending of each other will inevitably enlighten the expansion and innovation of thinking[5]. According to the requirements of the "Guidelines for the Construction of Modern Industry Colleges (Trial)" issued by the Ministry of Education and the Ministry of Industry and Information Technology, in order to solidly promote the construction of new liberal arts, further deepen, expand, break through, and start again, and coordinate the promotion of new liberal arts and new agricultural sciences, new medical sciences, and new sciences. The integrated development of engineering and the comprehensive improvement of talent training capabilities. It is imperative that universities and local governments, industry enterprises and other multi-agents build, co-manage, and share modern industrial colleges to cultivate applied, compound, and innovative talents. And initiatives.

\subsection{Cocos digital technology and its industrial ecosystem}

The Cocos engine team has been committed to providing advanced technology and services for the digital content industry. Its self-developed "Cocos Engine" series of products include the second-generation game editor Cocos Creator, Cocos Creator 3D, and the world's popular open source engine framework $\operatorname{Cocos} 2 \mathrm{~d}-\mathrm{x}$ and other products. In the past ten years, Cocos Engine has played its role of technical support in the industry while focusing on building an education ecosystem. It is the first batch of industry-university cooperative education support enterprises by the Ministry of Education.

\subsection{Cocos Digital Technology Industry College Construction Goals}

To build the Cocos Digital Technology Industry College, the goal is to take the urgent needs of the development of local cultural industries and red tourism and cultural industries as the traction, combine the characteristics of liberal arts and sciences, closely link the Cocos digital engine technology and industrial ecosystem, and focus on the integration point with local economic and social development Optimize the professional structure, enhance the vitality of running schools, explore the effective connection of industry, innovation, education and other block chains. At the same time, establish a new type of information, talent, technology and material resource sharing mechanism, improve the collaborative education mechanism, and innovate the corporate mentor evaluation mechanism. Establish a linkage development mechanism between higher education and industrial clusters, and build a demonstrative talent training system that integrates talent training, scientific research, technological innovation, corporate services, student entrepreneurship, etc., to provide government and local industries with various digital displays, smart cities, Contribute to the development of the game animation industry.

\subsection{Cocos Digital Technology Industry College Construction Task}

- Innovative talent training model

Facing the entire industry chain of digital content display, VR/AR (virtual reality/augmented reality), game animation, online education, etc., cultivate applied, compound and innovative talents urgently needed by the industry. The COCOS Digital Content Industry College will set up one or more technical classes according to the local characteristics of digital content industry talents and project research and development needs, "introducing enterprises to teach", reform and innovate the original training model, and promote cooperation, project, order, and enterprise Practical teaching and other teaching modes. Promote the integration of course content and the development of COCOS digital content technology, the connection between the teaching process and the digital content production process, and the integration of talent training with the needs of the ecological chain industry. Promote open cooperation between schools and enterprises, integrate innovative elements and resources such as schools, enterprises, industrial chains and technologies, and condense the application-oriented talent training model of deep integration of production and education and multi-party collaborative education.

- Improve the quality of professional construction Focusing on key development areas such as regional characteristic culture and red culture, actively adjust the professional structure, focus on creating special advantages and promote the development of professional clusters. Closely connect the industry chain, realize the cross integration of multiple disciplines, and support the rapid development of several related technical disciplines in the same industry chain; according to the frontier trend of the digital content industry, integrate relevant disciplines to meet the needs of multi-position and multi-technical talents in digital content production. Cultivation, breaking the original teaching plan between departments and majors, providing students with a real industrial environment, advocating a learning platform that promotes one specialization and multiple abilities, and promotes collaborative innovation. At the same time, a professional construction steering committee is established to introduce digital content industry standards and COCOS ecological resources. Introduce COCOS official technical certification, promote the coordination and linkage of professional certification and entrepreneurship and employment qualifications, and improve the standardization and internationalization of professional construction. 
- Development of school-enterprise cooperation courses

Combined with the official COCOS curriculum system, schools and enterprises jointly complete the compilation of teaching materials and curriculum construction, design the curriculum system, and optimize the curriculum structure. Accelerate the iteration of course teaching content, promote the scientific connection of course content with industry standards, production processes, project development and other industry needs based on the dynamic development of the COCOS ecological chain, and build high-quality school-enterprise cooperation courses, teaching materials and engineering case collections. Relying on the COCOS engine technology, closely integrating the actual situation of the industry, innovating teaching content, methods and means, increasing the proportion of comprehensive and design practice teaching, and taking real projects and product designs of industry enterprises as practical links such as graduation design and curriculum design The source of the topic. According to professional characteristics, use real development environment to carry out immersive real case teaching, focus on improving students' hands-on practical ability, and effectively improve students' awareness of industry and ability to solve complex problems.

- Build an internship training base

Based on the technology and development process of COCOS digital content production, innovate the school-enterprise cooperation model, and build a practical teaching and practical training internship environment based on industrial development and innovation needs. Establish an independent physical space, coordinate practical teaching resources, make full use of the high-quality resources of the COCOS ecological chain, and build a functionally intensive, open and shared, and efficient cross-professional practical teaching and competition platform. At the same time, the COCOS engine $R \& D$ technology will be introduced to build a digital content service outsourcing production base, an innovative $\mathrm{R} \& \mathrm{D}$ base, and an order-based talent training base. Become a school-enterprise integration with production, teaching, research and development, innovation and entrepreneurship functions, and an experiment, practical training and practice base for industry-university-research collaboration.

- Building a high-level teaching team

Strengthen teacher training, regularly carry out teacher training, technical exchanges, seminars and other projects with companies, and build COCOS Digital Content Industry College into a "dual-teacher dual-energy" college. Employ outstanding technical personnel of the company to teach and guide jointly to build a high-level teaching team.

- Build a service platform for industry-university -research

Based on the COCOS Digital Content Industry College, we will cooperate with relevant municipal departments and enterprises to jointly establish the "Digital Creative Research Institute" and the "Big Data Research Institute", give full play to the comprehensive advantages of the school's talents and professions, and carry out collaborative innovation around the key issues of industrial technology innovation, To realize the knowledge spillover of universities directly serve the local economic and social development, promote the transformation and application of production results, promote the digital transformation and upgrading of local industries, and solve the technical problems encountered in the technological upgrading and development of local departments and industries at the same time, and cultivate for the local More high-end research talents. At the same time, it can also be used as a "digital technology display base" and "data analysis base" for government departments and enterprises.

\section{Cocos DigitAL TECHNOLOGY INDUSTRY College Construction Guarantee SYSTEM}

\subsection{Environmental construction}

Both the school and the enterprise invest resources, including funds, professional laboratory equipment, software platforms and systems, teaching resources and project cases, among which hardware equipment investment is not less than $50 \%$.

Planning a dedicated site for the independent physical space of the Industrial College for teaching, practice, research and development office, etc. Among them, build incubators, project accelerators, famous teacher studios/enterprise workshops, etc.

\subsection{Supporting funding}

The supporting funds are used for the construction of the project, including: platform construction, teacher construction, laboratory construction, professional teaching resource library construction, etc. To ensure the systemicity of talent training + platform + resource structure.

\subsection{Co-management and organizational structure}

With school-enterprise as the dual main body of management and operation, a council is established, and the industrial academy/project responsibility system under the leadership of the council is adopted, and both parties manage and operate jointly.

The board of directors is composed of leaders in charge of the school, leaders of various departments, and corporate leaders. Mainly responsible for formulating long-term plans for the development of industrial colleges/projects, and making decisions on major issues in the reform and development of industrial colleges/projects; the dean of the industrial colleges is mainly responsible for implementing the decisions of the council and managing the construction and operation of industrial colleges/projects Group; professional construction committee: composed of professional leaders and enterprise technical supervisors involved in various 
cooperation majors, mainly responsible for organizing professional construction and development research; industrial talent service group center: school academics and employment staff, enterprise HR, enterprise It is composed of the head of the employing department and the talent service manager of cocos college. Mainly responsible for the research and analysis of the needs of industrial talents, and provide the professional construction committee with enterprise demand information, employer feedback information, student employment services, etc.; joint teaching and research center: professional construction teaching and research personnel of the school, enterprise technical experts, senior corporate lecturers of cocos college, Composition of industrial engineers. Mainly engaged in the research and practice of advanced engineering education theory, participating in professional construction, and responsible for curriculum research and project development; professional teaching and research section: It is composed of school professional construction related teaching and research personnel, enterprise technical experts, and senior corporate lecturers of cocos college. Responsible for the management of teaching resources and case resources in the development of professional talent training programs and teaching plans; teacher training and certification center: composed of school teacher training department, cocos lecturers and staff. Mainly responsible for the teaching ability training and certification of the professional teachers of the industrial college; the project office is mainly responsible for the college's daily administrative management and student management.

\section{ConCLUSION}

The construction of the Cocos Digital Technology Industry College under the background of the new liberal arts takes Lide as the fundamental task and student development as the center, breaking through the traditional discipline construction and talent training path dependence, giving full play to the advantages of the local industry and giving play to the important education of the enterprise The main role is to deepen the integration of industry and education, promote universities to explore the construction model of digital technology industry colleges, build strong specialties and improve the collaborative mechanism of talent training, and create a large number of high-quality application-oriented, compound-oriented and innovative talents required by the industry , To provide talent support and intellectual support for improving industrial competitiveness and gathering new development momentum. At the same time, in the process of achieving the goal of cross-border integration of disciplines, it has also firmly promoted the integration of new liberal arts with new agricultural, new medical, and new engineering.

\section{REFERENCES:}

1. Ministry of Education of the People's Republic of China. Notice of the General Office of the Ministry of Education on the implementation of the "Double Ten Thousand Plan" for the construction of first-class undergraduate majors.

2. Fan Liming, "Cohesion, Innovation and Construction to Create a New Future of Liberal Arts Education". "Higher Education in China", Issue 24, 2020.

3. China Social Sciences Journal. Construction of "New Liberal Arts" in Colleges and Universities: Concepts and Actions [EB/ OL].[2019-03-21].

4. General Office of the Ministry of Education, General Office of the Ministry of Industry and Information Technology. "Guidelines for the Construction of Modern Industry College (Trial)". [2020-07-30].

5. Wu Guanying, "Thoughts on the Construction of Animation and Digital Media Art from the Perspective of New Liberal Arts". "Media". No. 5, 2021.

6. "Recommendations of the CPC Ganzhou Municipal Committee on the formulation of the city's fourteenth five-year plan for national economic and social development and long-term goals for 2035." [2021-01-20]. 